\title{
A designer's approach: how can autistic adults with learning disabilities be involved in the design process?
}

\author{
Katie Gaudion, Ashley Hall, Jeremy Myerson \& Liz Pellicano
}

\begin{abstract}
Autistic adults with limited speech and additional learning disabilities who are often excluded from design research are at the heart of this project. These are people whose perceptions, experiences and interactions with their surroundings are unique, but also are people who may not be able to communicate verbally their differences to the remaining $99 \%$ of the population. This, in combination with their distinctive cognitive profile, has resulted in a lack of studies involving people living with autism, and consequently their life experiences may neither be heard nor understood and remain largely unexplored. By reflecting upon the ongoing design collaboration between The Helen Hamlyn Centre for Design and the autism charity The Kingwood Trust, this paper reflects on the approach and methods used in three design studies. Particular attention is paid towards the careful selection, adaptation and development of collaborative design methods for autistic adults and their support staff to be involved. By working beyond the boundaries of a neurotypical culture, the project aims to support the greater goal of improving the everyday experiences of people living with autism by breaking down the barriers to participation.
\end{abstract}

Keywords:: autism, adults, learning disabilities, participatory design, environment, sensory preferences

\section{Autism spectrum disorder}

Autism spectrum disorder is a lifelong complex neurodevelopmental condition, which affects the way that a person interacts with and experiences the world around them (American Psychiatric Association 2010). It is a spectrum condition that affects people in vastly different ways. Someone with autism might be sociable, while others find social relations difficult. Some have learning disabilities while others possess high levels of intellectual ability. It is no longer considered rare: it is estimated that 1 in 100 people is diagnosed with autism (Baird, Simonoff, and Pickles 2006; Brugha et al. 2009).

Although autism is most often associated with its effects on social communication and interaction, the latest revision of diagnostic criteria (the Diagnostic and Statistical Manual of Mental Disorders, Fifth Edition; DSM-5 2013) recognise the unusual way that people living with autism respond to sensory input. These so-called 'sensory sensitivities' can affect a person's ability to interpret, filter and regulate sensory information, leading to a person becoming hypersensitive (over-stimulated) and/or hyposensitive (under-stimulated) to incoming information, thereby influencing how they experience the environment around them. For example, while some people living with autism find certain sounds (e.g. dogs barking) or visual input (e.g. fluorescent lights) disturbing, others seek out and take pleasure in such stimuli. 
These sensory sensitivities can have an enormous - and often negative - impact on people's everyday lives (Pellicano, Dinsmore, and Carman 2013). Surprisingly, however, a person's relationship with the environment is rarely featured within autism research, which instead focuses largely upon the underlying biology and causes of autism (Pellicano, Dinsmore, and Carman 2014). The revised DSM-5 is therefore an important milestone that puts the sensory environment back onto the roadmap within autism research, creating a natural avenue for designers to explore how their deep understanding of the sensory quality of materials, skills in making and spatial/visual thinking can develop new modes of non-verbal communication, dialogue and understanding around an autistic person's everyday experiences.

Kanner (1943) and Asperger (1944) formed the basis for our understanding of autism. The introduction to Kanner's seminal article $(1943,217)$ features a pertinent quote:

To understand and measure emotional qualities is very difficult. Psychologists and educators have been struggling with that problem for years but we are still unable to measure emotional and personality traits with the exactness with which we can measure intelligence. (Rose Zelig)

On reflection, the description 'We are still unable to measure emotional and personality traits' could have set the precedence thereafter for autism research, which has largely situated itself within a positivist approach, measuring and representing people living with autism in quantitative terms: as numbers on a bar chart or percentages on a pie chart. This approach, however, misses the opportunities that qualitative insights can provide for different types of new knowledge, including an autistic person's subjective lived experiences in relation to their environment, how they use it and are influenced by it.

Design therefore complements existing autism research by focusing not just on the person (Being) but looks externally at the person in combination with the environment in which they live (Being-in-the-world, Heidegger). This research also echoes the perceptual psychologist James Gibson's key concept 'Ask not what's inside your head, but what your head's inside of' (Mace 1977, 43). Gibson introduced the term 'affordance' in the article The Theory of Affordances (1977) and further explored it in The Ecological Approach to Visual Perception (1979). He describes affordance as the 'fit' between a person and the environment, which then creates opportunities for actions whether they are good or bad. It is therefore the 'fit' that determines these opportunities for actions. Gibson's concept of affordance was used as a key mechanism to trigger understanding and action in others. This design project proposes that it is the non-human material infrastructure of the environment and what it affords that is critical to an autistic persons understanding of themselves, other people and the world around them. It further argues that it is vital for the designer to connect with people living with autism to develop better understanding of how they experience the environment.

\section{Existing design research}

One of the earliest design and autism-related study was in 1971 entitled 'A Playroom for Autistic Children and its companion therapy project' (Richer and Nicoll 1971). Following on from this in the Netherlands in the 1970's came the design of Snoezelen ${ }^{\circledR}$, an environment designed to stimulate the primary senses for leisure and relaxation often used by people 
living with autism, which has since expanded internationally and can be found in schools, hospitals and even prisons.

More recently, there have been a growing number of design researchers who are considering the physical environment as an important point of intervention for people living with autism, by improving the design of schools (Beaver 2003, 2011; Gumtau et al. 2005; McAllister and Maguire 2012; Mostafa 2008; Tufvesson and Tufvesson 2009; Vogel 2008), supported living accommodation (Ahrentzen and Steele 2009; Brand 2010; Kanakri 2013; Lopez and Gaines 2012; Woodcock et al. 2006), outdoor spaces (Gaudion and McGinley 2012; Linehan 2008; Herbert 2003; Hussein 2010; Menear, Smith, and Lanier 2006; Sachs and Vincenta 2011; Yuill et al. 2007) and most recently a town (Decker 2014). Despite this emerging field, for some of these studies importance was placed on the design outputs and generic design guidelines, with little emphasis on the process of how they evolved and attention paid towards the participation of people living with autism within the design process.

Design projects that have highlighted the involvement of people living with autism are largely associated with interactive technologies, virtual environments, apps and software to improve communication skills. Several models have been developed which explore at what level people living with autism can participate in the design process. Most notably Benton et al.'s (2011, Benton and Johnson 2014) IDEAS (Interface design experience for the autism spectrum) participatory design method, itself inspired by the structured learning approach TEACCH (Treatment and Education of Autistic and related Communication handicapped Children). Also, Druin's (1999) Cooperative Inquiry, which describes the different levels of a child's engagement within the design process. Druin's cooperative enquiry informed the development of Guha et al.'s (Guha, Druin, and Fails 2008) Inclusionary Model that is composed of three layers: (1) levels of involvement, (2) the nature and severity of the disability and (3) the availability and intensity of the support.

Design studies in which attention was paid to the designer's approach include Van Rijn's (2012) Ph.D. entitled 'Meaningful Encounters', which developed an 'observe, reflect, theorize, try-out' framework to help designers engage with children living with autism. Autistic children were also involved within the development of Keay-Bright's $(2007,2009)$ ReacTickles software suite, through prototype exploration and using the model 'research, inspire, listen and develop'. Existing studies relating to autism combined with extensive research drawn from the Echoes - Technology-Enhanced learning project (Frauenberger, Good, and Keay-Bright 2010; Frauenberger, Good, and Keay-Bright 2011; Frauenberger et al. 2012a, 2012b), has revealed important gaps, questions and concerns which this project aims to address and build upon, a selection of which are described below.

- The majority of existing design research is concerned with children living with autism and only a few projects focus on adults (Brand 2010, Brand and Gaudion 2012; Gaudion and McGinley 2012, 2013, 2014; Madsen et al. 2009; Parsons et al. 2000; Ahrentzen and Steele 2009; Decker 2014). As most people living with autism will spend the majority of their lifetime as an adult, this lack of design research is of concern. To rely entirely on methods designed for children is highly inappropriate as 
there are important differences between children and adults (whether a person is living with autism or not).

- Autism is a spectrum disorder yet the majority of design research is concerned with people who are 'high-functioning'. Fewer projects focus on those with limited speech and additional learning disabilities (Brand 2010; Brand and Gaudion 2012; Gaudion and McGingley 2012; Gaudion 2013, 2014; Keay-Bright 2012a, 2012b; Khare and Mullick 2010; Hourcade, Bullock-Rest, and Hansen 2012). As between 44\% and $52 \%$ (NAS) of people living with autism have a learning disability, it is important that they are also considered.

- The majority of existing design research is framed around the general classification of autism, which fails to consider the heterogeneous nature of autism and focuses on a person's deficits, i.e. poor social interaction (Francis, Balbo, and Firth 2009; Khare and Mullick 2010). This general classification does not tell us anything about individual strengths and interests. A number of design guidelines relating to autism and the built environment have been developed in this way (Humphrey 2005; Beaver 2003, 2010; Ahrentzen and Steele 2009).

This project affiliates with studies that take a bottom-up approach, whose main starting point was to explore an autistic person's sensory perceptual experience with the physical environment (Baumers and Heylighen 2010a, 2010b; Sanchez, Vázque, and Serrano 2011; Robinson 2012; Loveland 1991, 1994, 2001; Williams et al. 1999, 2005; Williams and Kendell Scott 2006). Baumer's et al. looked at 'auti-biographies' of a persons' experience with the environment. This 'taking on an autism perspective' forms the springboard for this project. To help describe a person's experiences of their home environment, this project drew upon theories stemming from phenomenology (Husserl, Heidgger, Merleau-Ponty), which is growing in popularity within autism research and design (Seamon and Mugerauer 2000, Seamon 1993; Cashin 2003; Norberg-Schulz 1991; Sirowy 2010).

\section{Three design studies}

Three design studies were carried out each lasting for one year. Each explored a person's interaction and reaction to three environmental, domestic contexts: study one (the garden), study two (everyday objects) and study three (the interior). All three vary in scale, action opportunity and the degree of control of sensory elements. The garden, for example, is the least controllable environment due to the less predictable nature of the outdoors. The main objective of each design study was to involve adults living with autism in the design process to investigate how they currently experience their environment, and to inform the design of space, objects and activities that are more meaningful to them.

The research adopted a strengths-based (rather than a deficits-based) approach by exploring a person's 'triad of strengths', including his/her (1) sensory preferences, (2) special interests and (3) different action capabilities. This was vital to the project and the design process. A person's strengths also helped the designer to connect and communicate with the participants, and adapt the affordances of each environment in three distinct ways where positive experiences could be extended. This involved (1) creating an entirely new 
garden, (2) adapting an existing everyday object (a bubble-blowing vacuum cleaner) and ( 3 ) adding artworks into the home (Figure $1(\mathrm{a})-(\mathrm{c}))$.

Figure 1 (a) Kingwood College garden. (b) Bubble blowing vacuum cleaner. (c) Artworks selection.

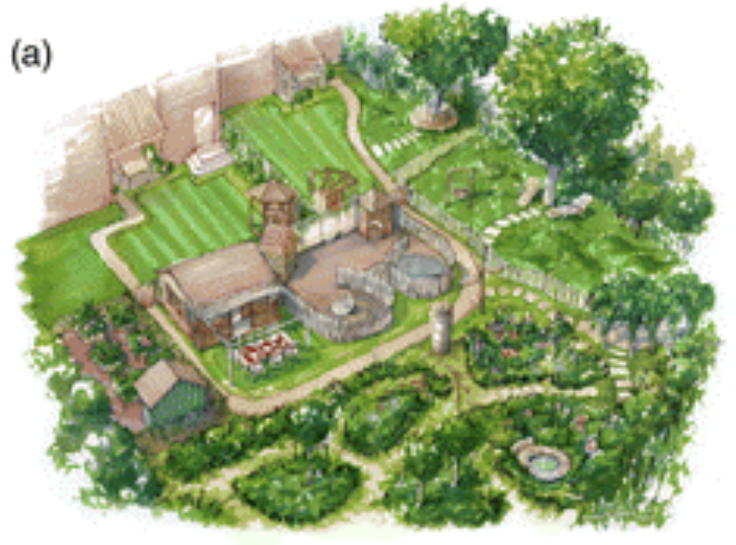

(b)

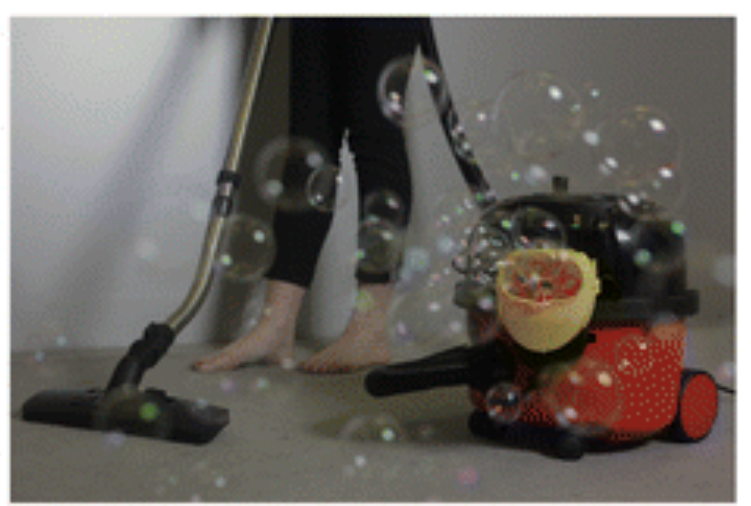

(c)

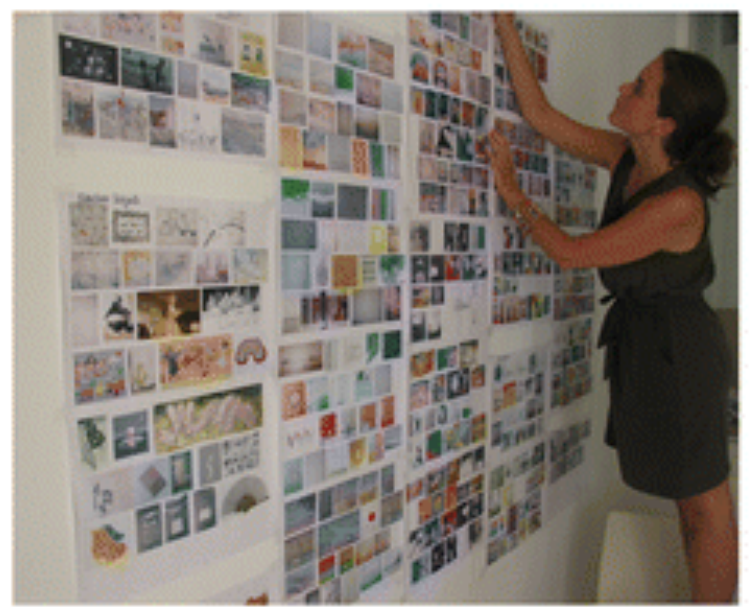

\subsection{Three design stages}

There are inherent difficulties in working with individuals who have learning disabilities and little spoken language. Autistic people can be extremely uncomfortable in the presence of, or interacting with, others. Therefore, a key consideration was the participants in the design process, and their scope for agency. This work combines the views and experiences of multiple informants - the autistic adult (A), their support staff/family member (S) and the designer (D). 
Three participant configurations $(A-S-D / A-S / S-D)$ were identified within the design process, which formed the three design stages (Figure 2). Each design stage lasted approximately three months and the participant configuration presented different objectives and challenges that influenced the selection and facilitation of the methods used. Stage one largely involved one-one and/or triadic interactions between all participants, inviting 16 autistic adults and their support staff to participate. Stage two largely involved one-to-one interactions and invited up to 39 autistic adults with their support staff to participate. Stage three involved group activities involving 60 support staff.

Figure 2 Participants in stages one-three of the design process.
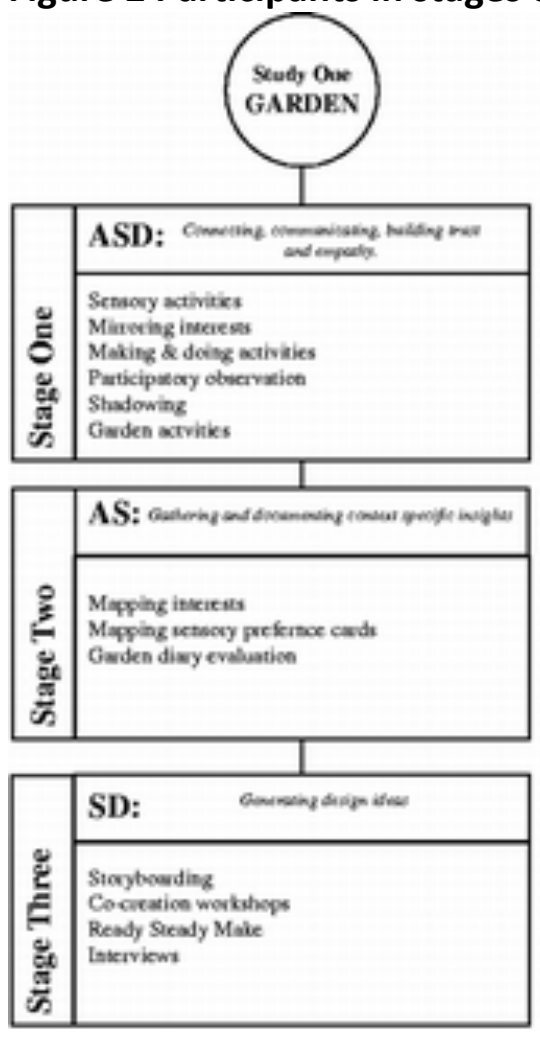
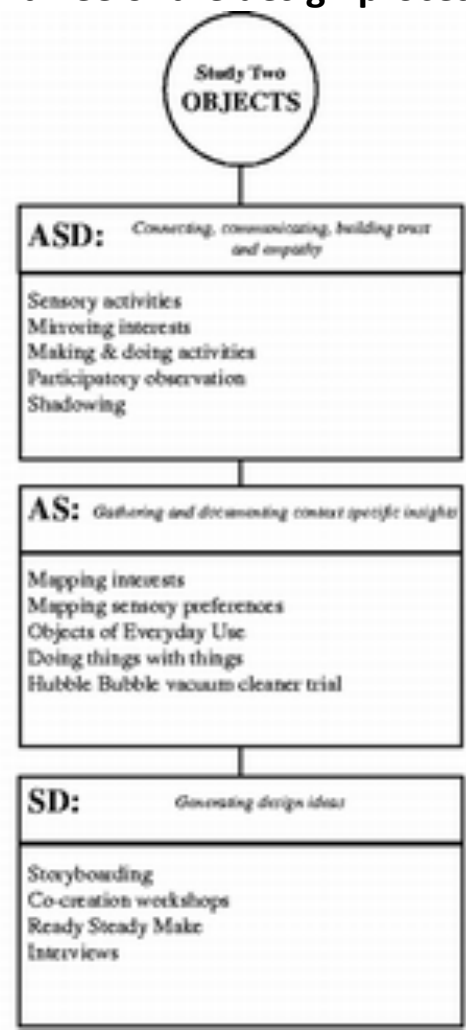
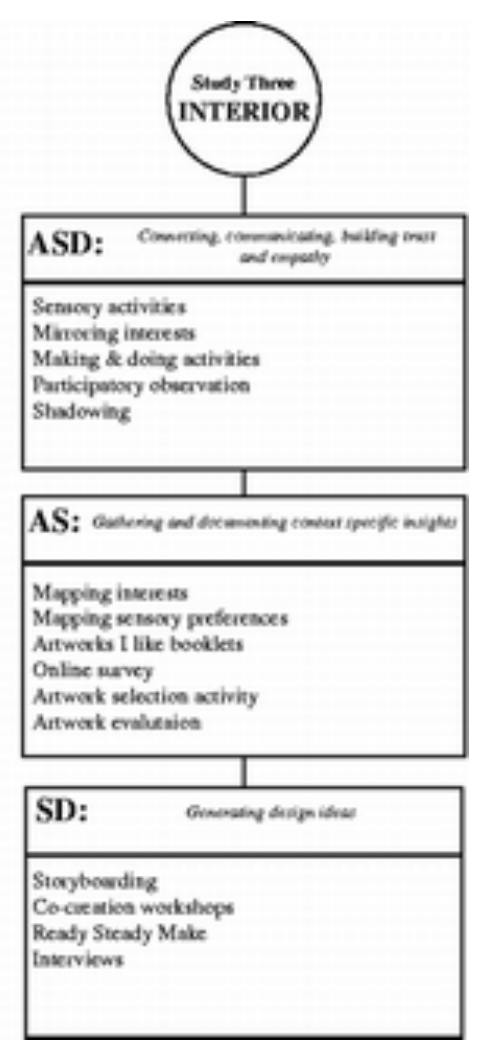

\section{Stage one}

The first stage of the design process involved all three participants (A-S-D): an autistic adult, their support staff and the designer. Positive relationships were key, so the design methods were used to develop trust and empathy between each person. The designer's skills in communicating, listening, observing and adapting were of particular importance. To explore different ways of communicating, the designer spoke literally, avoided metaphors and abstract scenarios that were not too embedded in a neurotypical context. For this stage, the designer completed a Makaton and Montessori for autism course and drew upon previous experience with Snoezelen environments. Below are two methods used within this stage.

\subsection{Sensory activities}

The project proposes that affordances are the key mechanism that designers can use to trigger understanding and action in others. Therefore, instead of facilitating activities with specific tasks and goals framed within a neurotypical context, the sensory activities were led 
by the participants living with autism to explore their action capabilities to create tangible clues and insights in how they may choose to afford their environment.

The sensory activities were a physical and active extension of the What Do You Like? Kingwood Sensory Preference Cards (Figure 6(a)). Each activity was led by the autistic participant, which invited them to engage with objects (rather than engaging with people and having to achieve specific tasks) to help explore and test the boundaries of their sensory preferences in an engaging yet relaxed manner. The props were chosen for their sensory properties in terms of touch, sound, sight, smell, and movement, and were abstract in shape. The function and archetype of the props were deliberately undefined, which helped the designer to observe a person's interactions without them being distracted by their subjective prior knowledge or the intended functionality of the prop. The props were important tools that helped to mediate non-verbal communication between the autistic participant, designer and support worker through their interaction and exchange (Figure 3).

Figure 3 Connecting and communicating with sensory props.

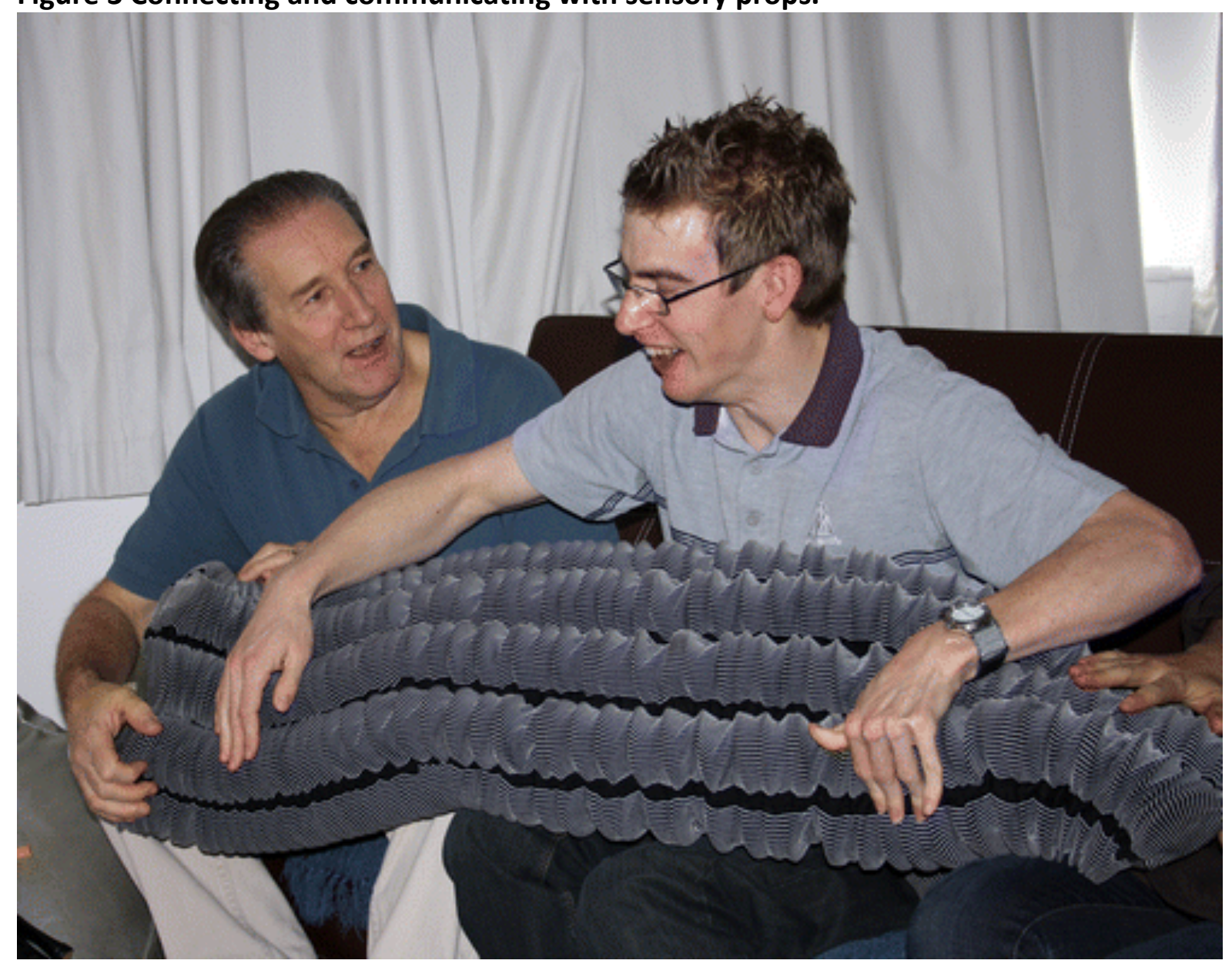

The information derived from this activity provided a rich palette of sensory preferences and action capabilities about each participant. For example, Tom enjoyed the props that made a sound or movement to his motion of tapping and Sarah liked the props that changed shape in response to her interaction. These insights then informed the development of props that were more specific to each person's preferences; for example Sheema (Figure 4), a free-hanging knitted structure specially designed for Tim, enabling him to create a safe space, whilst enjoying the company of others. 
Figure 4 Sheema.

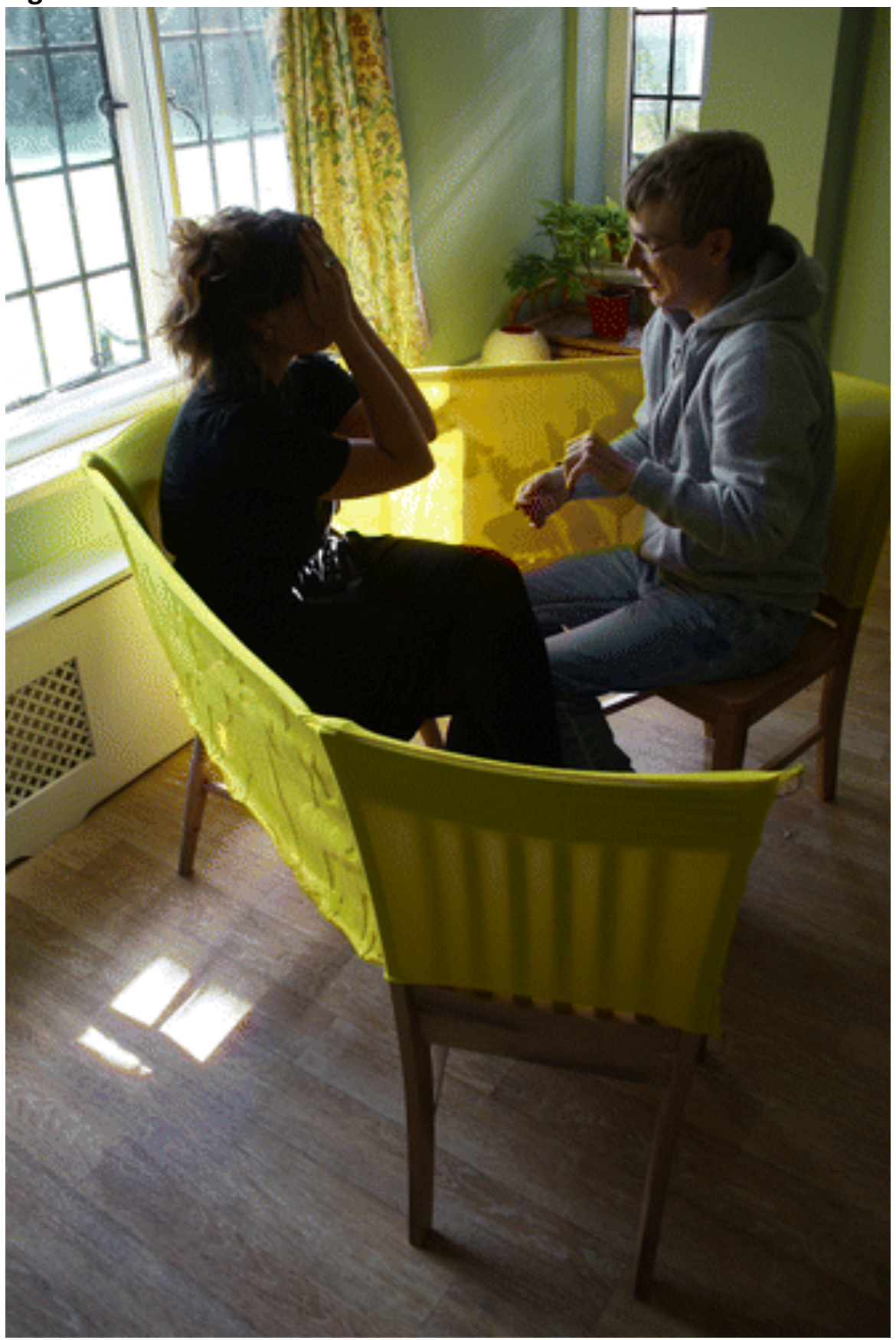




\subsubsection{Mirroring interests}

It is common for neurotypical people to engage in 'small talk' when meeting another person, but this can be highly inappropriate for people living with autism. Therefore, instead of questionnaires, interviews and conversations, the designer explored and engaged with the interests and things the autistic participants like to do as a way to create a dialogue and reciprocal relationships. For example, bubbles helped the designer to connect and communicate with James, an autistic participant who enjoys bubbles (Figure 5). The method of mirroring the interests and interactions of the participants followed the principles and methods used in intensive interaction (Nind and Hewett 1994; Caldwell 2010) in which we take the other person's lead and respond to things they do. This reciprocal relationship is also encouraged in Gernsbacher's (2006) paper 'Towards a behavior of reciprocity'. Mirroring a person's interests enabled the designer to break away from how they perceive the environment and instead approach it in the way a person living with autism might do. Consequently, joining in with the things a person likes to do created a meaningful interaction and shared experience.

Figure 5 The designer and James interacting with bubbles.

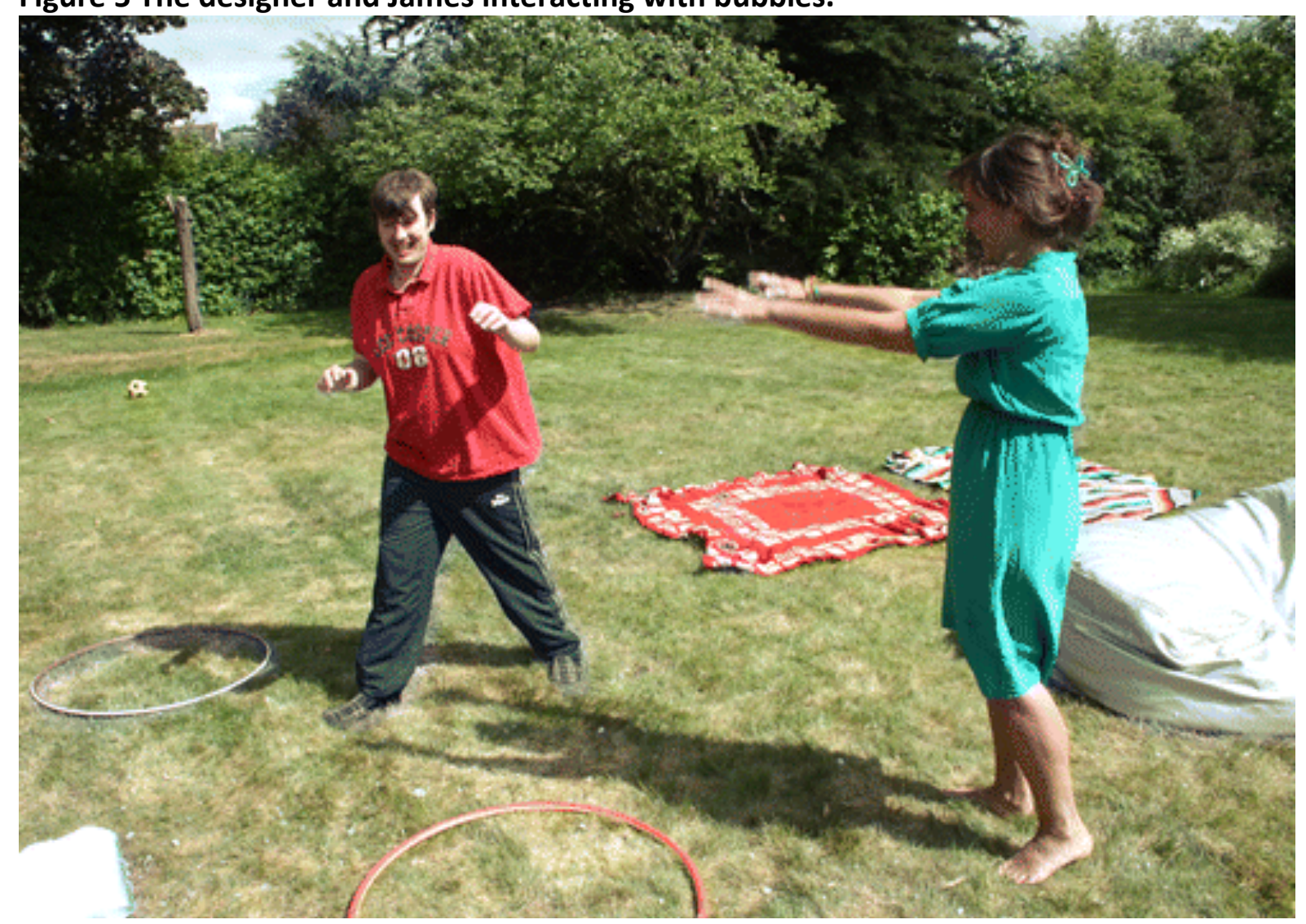

\subsubsection{Reflections}

The designer's observations during this stage highlighted how the things she found to be interesting might not be noticed or captured within existing literature or by support staff, whose priority and attention might be on personal care, health and safety. For example, it was only when the designer visited Jane (an participant living with autism) that she observed how Jane likes the sound of her washing machine on the last spin. A person's idiosyncratic relationship with their environment might remain abstract to another person 
unless they see or experience it for themselves. For example, because the designer observed several autistic participants enjoying bubbles whilst washing up, this influenced her design thinking which led to the development of the bubble blowing vacuum cleaner, which was a way to encourage a person to be more actively engaged in everyday activities, i.e. exploring ways of extending bubbles into other activities such as vacuum cleaning, so making the pleasurable element - the bubbles- intrinsic to more than one activity.

\section{Stage two}

This stage involved two different participants (A-S), autistic adults and their support staff building on the empathic understanding developed in stage one, to validate initial observations and interpretations. The aim of the design methods was to gather more context-specific information about the participants' experience with the garden, everyday activities and artwork preferences from which patterns and connections could be made. The designer developed a range of visual mapping tools some of which were succinct visual redesigns of existing lengthy questionnaires, using literal photographic imagery instead of words and tick boxes. This created a more engaging activity that invited the participants living with autism to express their thoughts and preferences, with the help of their support worker. Three design methods are described further.

\subsection{What Do You Like? Kingwood Sensory Preference Cards}

In response to existing questionnaires, i.e. The Adult/Adolescent Sensory Profile (Dunn 2002), whose wordy tick box format excluded the participants living with autism from taking part in expressing their sensory preferences, the What Do You Like? Kingwood Sensory Preference Cards were developed. What Do You Like? is a set of 75 cards (Figure 6(a)), each showing a different type of sensory experience relating to the home, described in simple words and illustrated by photographed images. The cards act as visual prompts for people with limited ability to verbally articulate their preferences (Figure 6(b)). Together with a family member, friend or support worker, the cards are used by an individual to express his/her likes, dislikes or neutrality about the image. This activity involved adults living with autism as active participants rather than relying on other people to express their sensory preferences on their behalf.

Figure 6 (a) What Do You Like? Kingwood Sensory Preference Cards. (b) Using the sensory preference cards. 
(a)
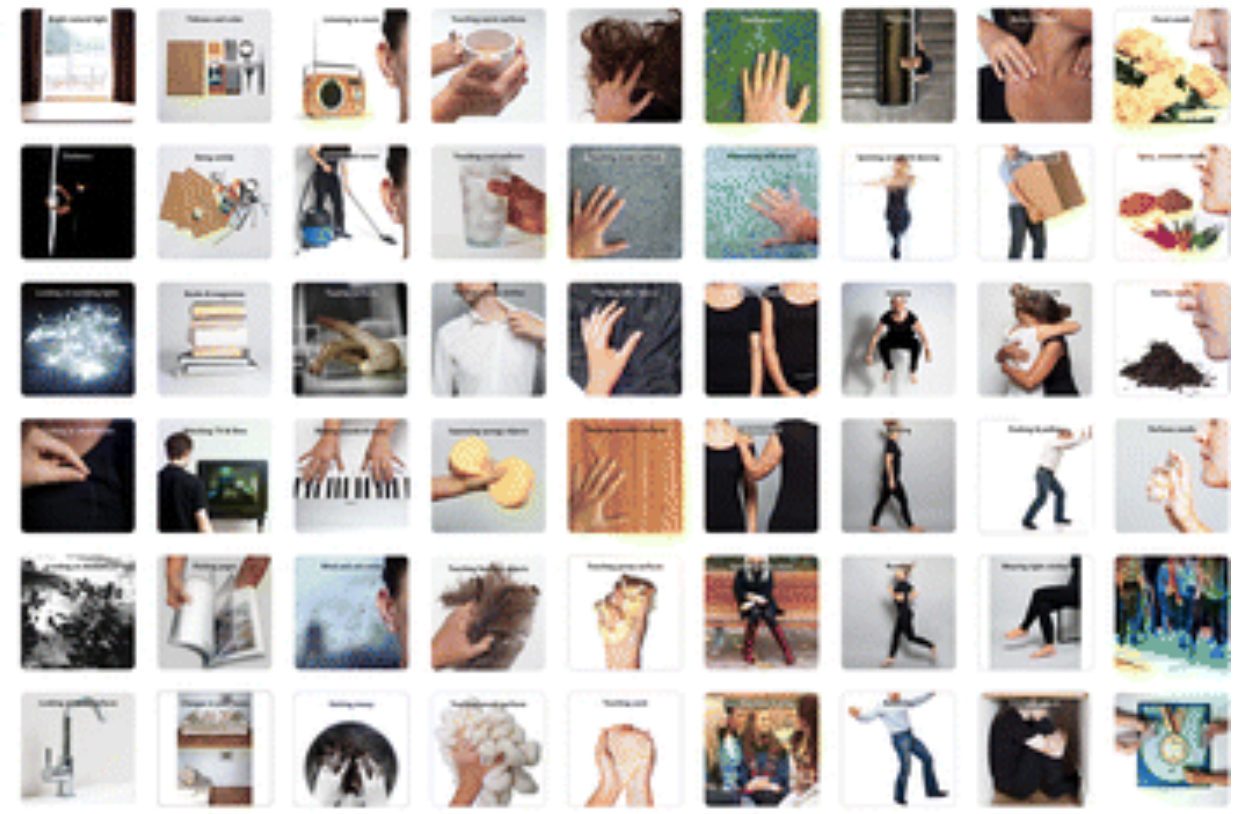

(b)

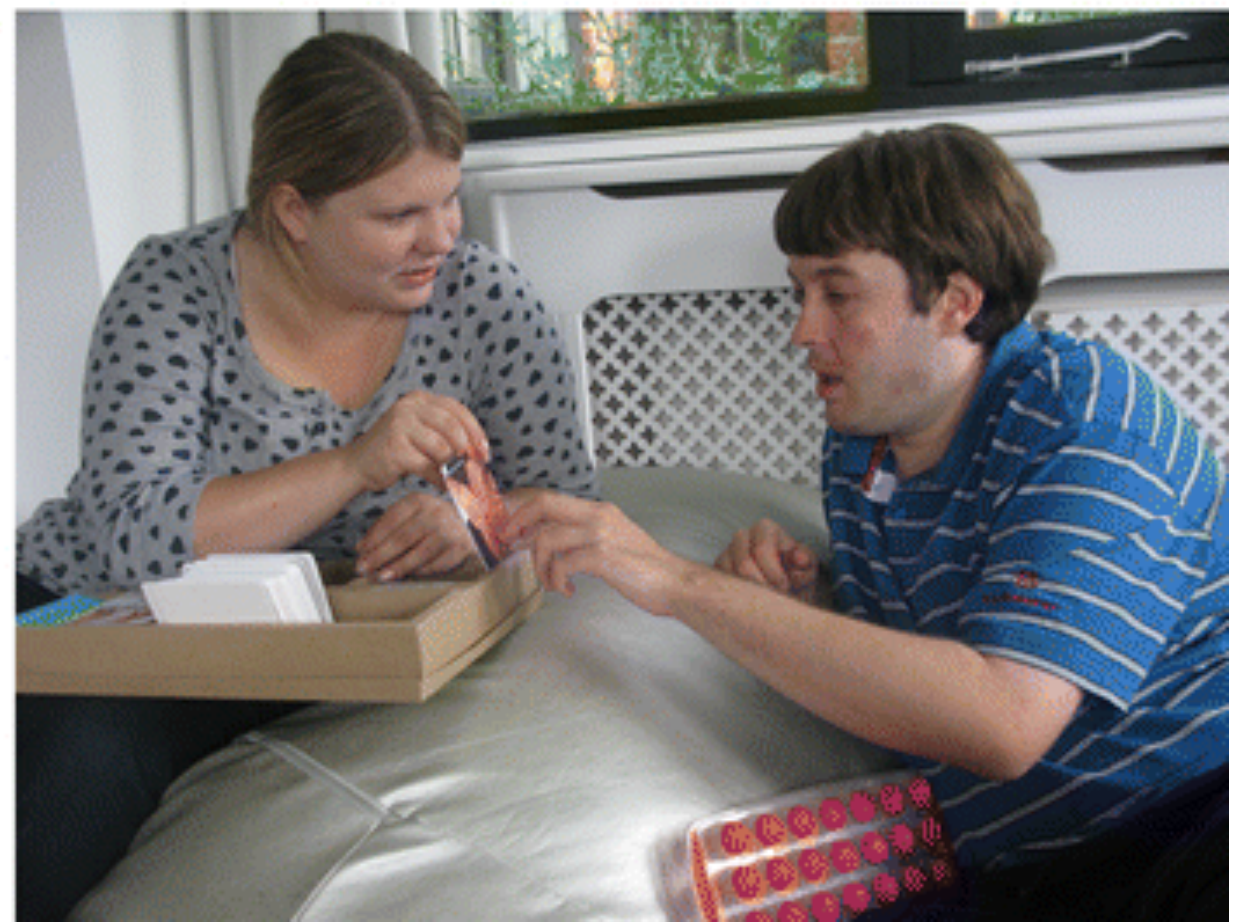

Once categorised, the cards create a visual sensory profile of an individual that may be used for making interior design decisions. The reverse sides of the cards are colour-coded by six sensory systems (touch, sight, sound, smell, vestibulation and proprioception), providing a quick reference, visual indication of the participants' preferred sensory system(s). For example, if a card selection reveals that a resident prefers their home to be neat and tidy, that he is sociable, enjoys listening to music, looking at twinkling lights, as well as shiny surfaces and reflections, then those cards form a 'mood board' to adapt living space to meet their sensory needs.

\subsubsection{Objects of everyday use}

In response to existing Instrumental Activities of Daily Living questionnaires (Lawton and Brody 1969) that determines a person's functional ability and level of independence, and do 
not take into account the heterogeneous nature of people's homes, the objects in their homes, and a person's different cognitive styles which may effect their ability to perform everyday activities, the designer developed a mapping tool called Objects of Everyday Use, a set of 43 cards, each showing a different everyday activity around the home, illustrated using simple words and photographic imagery (Figure 7). On the reverse side of each card, there are three simple questions about whether people liked/disliked the activity, and reasons for why and how much support was required. The cards act as visual prompts for the participants, who are often unable to verbalise their preferences. This encouraged the autistic participants with their support staff to work together and express how they perceive and experience everyday activities and the objects used to perform such activities. The cards enabled exploration of patterns and correlations between the most popular and least popular activities and the amount of support required to perform an activity. The cards revealed that a person's choice of everyday activity can be influenced by their sensory preferences, for example washing dishes in order to feel the bubbles or putting cutlery away to hear them chime.

Figure 7 Objects of everyday use cards.

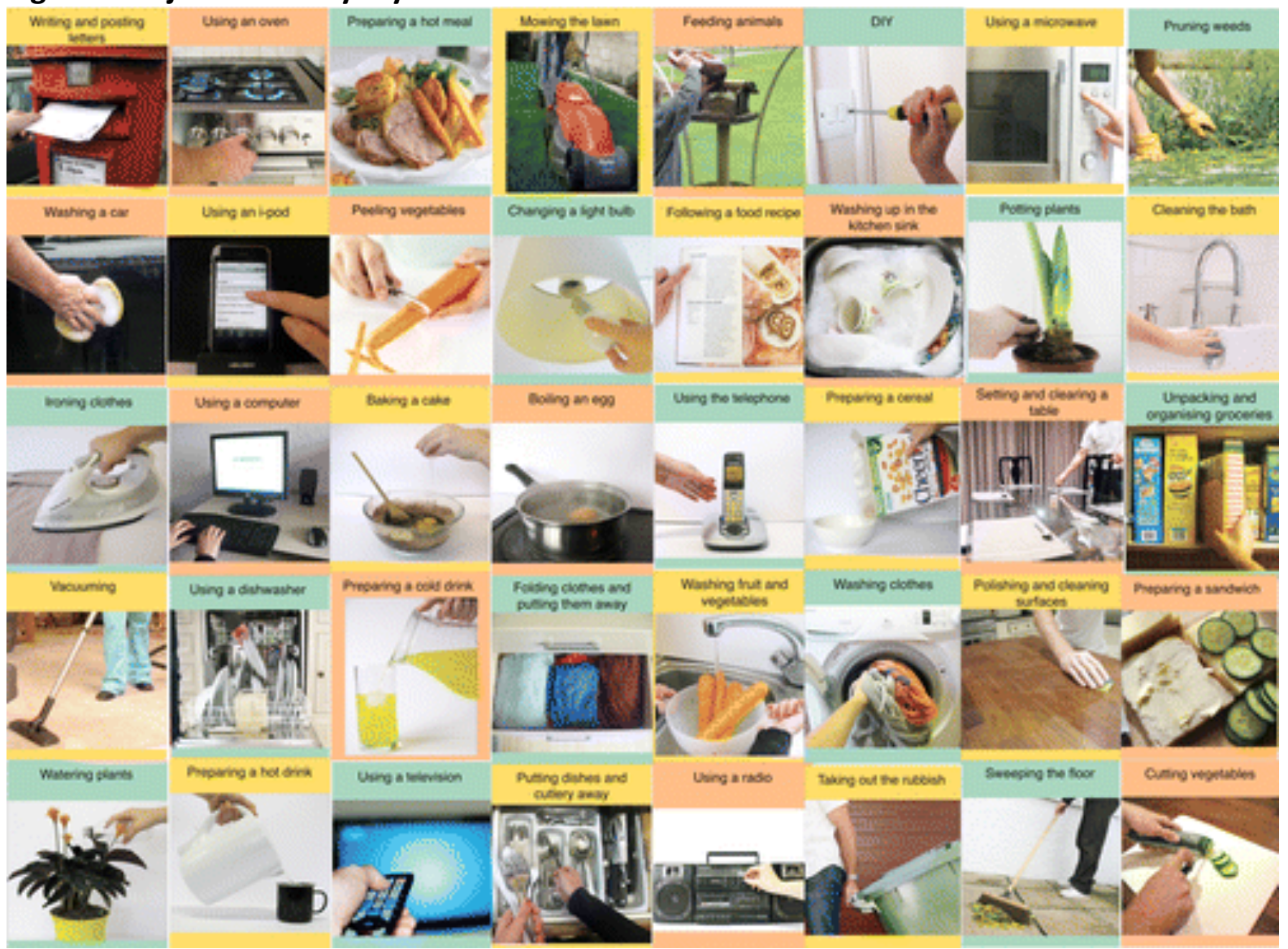

\subsubsection{Mapping interests}

A series of booklets were produced to help codify the special interests of adults living with autism. Each booklet was a visual extension of the questionnaire and taxonomy of special interests (Baron-Cohen and Wheelright 1999) in which 18 topics of popular special interests relating to autistic people were catalogued. The pocket-sized booklets each contained 20 
pages dedicated to one of the 18 interests. There was ample room for the participant to describe or draw their interests with visual prompts.

People's responses to the booklet revealed a broad range of special interests ranging from kangaroos to washing machines. To help identify patterns, each of these responses were visually represented using the image of a tree sporting 18 colour-coded branches, each representing a broad area of interest (Figure 8). Leaves were added to respective branches to identify more specific points of interest. The choice of the tree as an image was intended both as a metaphor for growth and as a device that encouraged the person represented to add more leaves to a branch. It was also a visual tool for support staff to stimulate ideas for further activities.

Figure 8 Tree of opportunity.

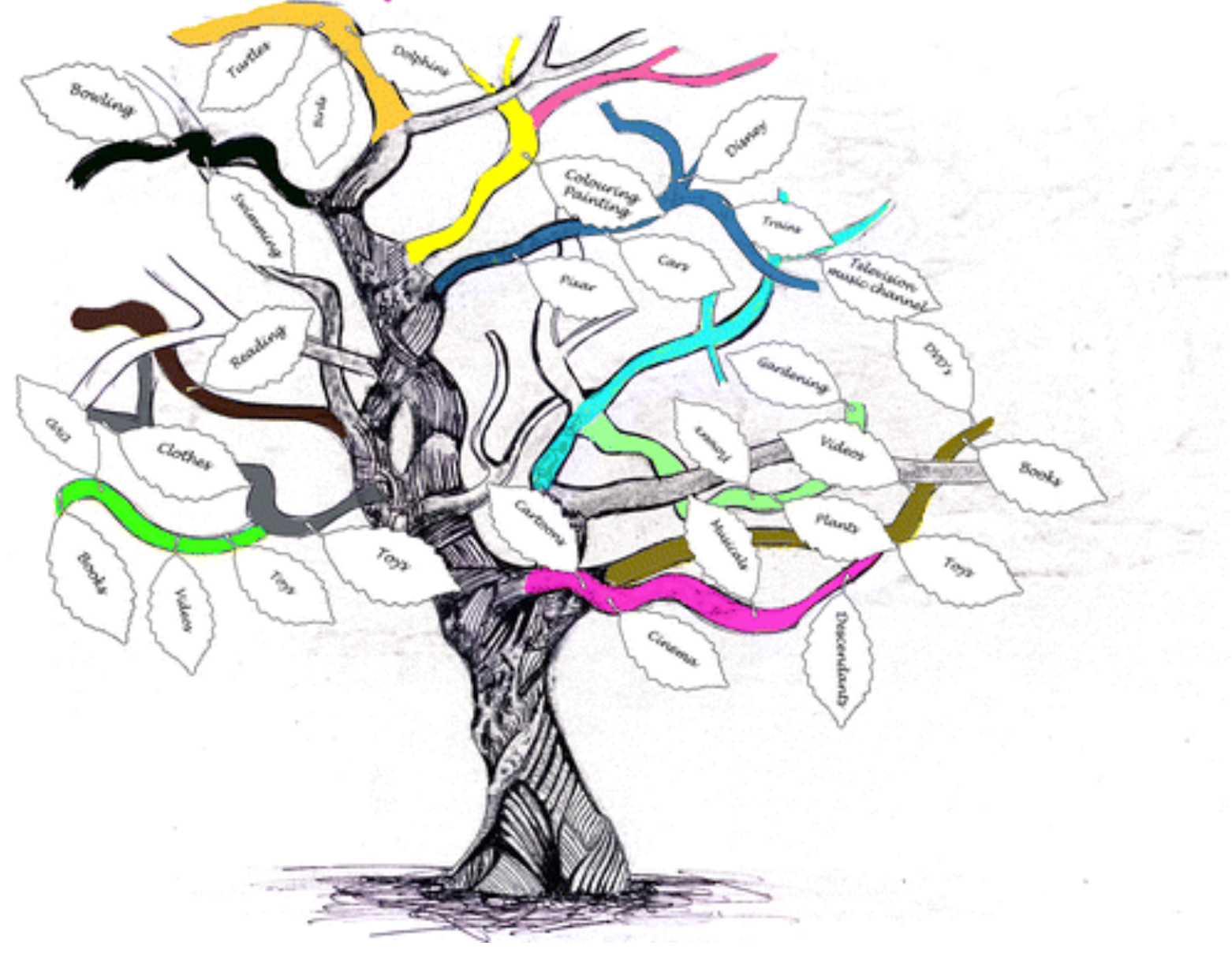

\subsubsection{Reflections}

As in stage one attaining the right information was difficult as it was often the things the support staff deemed irrelevant that were highly relevant to the designer. For example, when mapping interests, only timetabled activities such as swimming and bowling were recorded, leaving out the more idiosyncratic interests such as spinning objects. It was also important that the tools did not feel like additional work, but a fun activity between the support staff and person they support. One of the important challenges of this stage was the degree to which the support worker was able to translate, interpret and mediate communication between the designer and the autistic participants. 


\section{Stage three}

This stage predominantly involved the support staff and the designer (S-D). The methods in stages one and two generated rich insights about the autistic participant's triad of strengths, which informed the structure and content for the workshops in stage three and the starting point from which the co-creation process evolved.

In stage two, the support staff were essentially the mediators between the autistic adult and the designer, and an important challenge was to encourage the staff to foster a designer's perspective, to understand what insights might be interesting and relevant for them. This was an important ingredient for stage three, which involved a series of cocreation workshops that encouraged the support staff and family members to generate their own design ideas for the people they support. Two design methods used are described below.

\subsection{Co-creation workshops}

Through their collective observations, family members and support staff can be pivotal in understanding how an autistic person with limited speech might perceive and experience everyday life. Therefore, to generate design concepts, the designer held a co-creation workshop inviting Kingwood's support staff and family members to imagine how a proposed shared garden space might look and how it reflects a person's special interests (Figure $\underline{9}$ ). A simple, hypothetical garden layout was presented as a rectangular grass patch - essentially a blank canvas. A pack of cards illustrating possible garden features, spaces, furniture, flooring, partitions, utility, wildlife and activity ideas was given to each participant, who were asked to select those that were most appropriate to them or their family member. Additional blank cards could be used to represent new features or activities, as they emerged.

Figure 9 Co-creation garden workshop. 


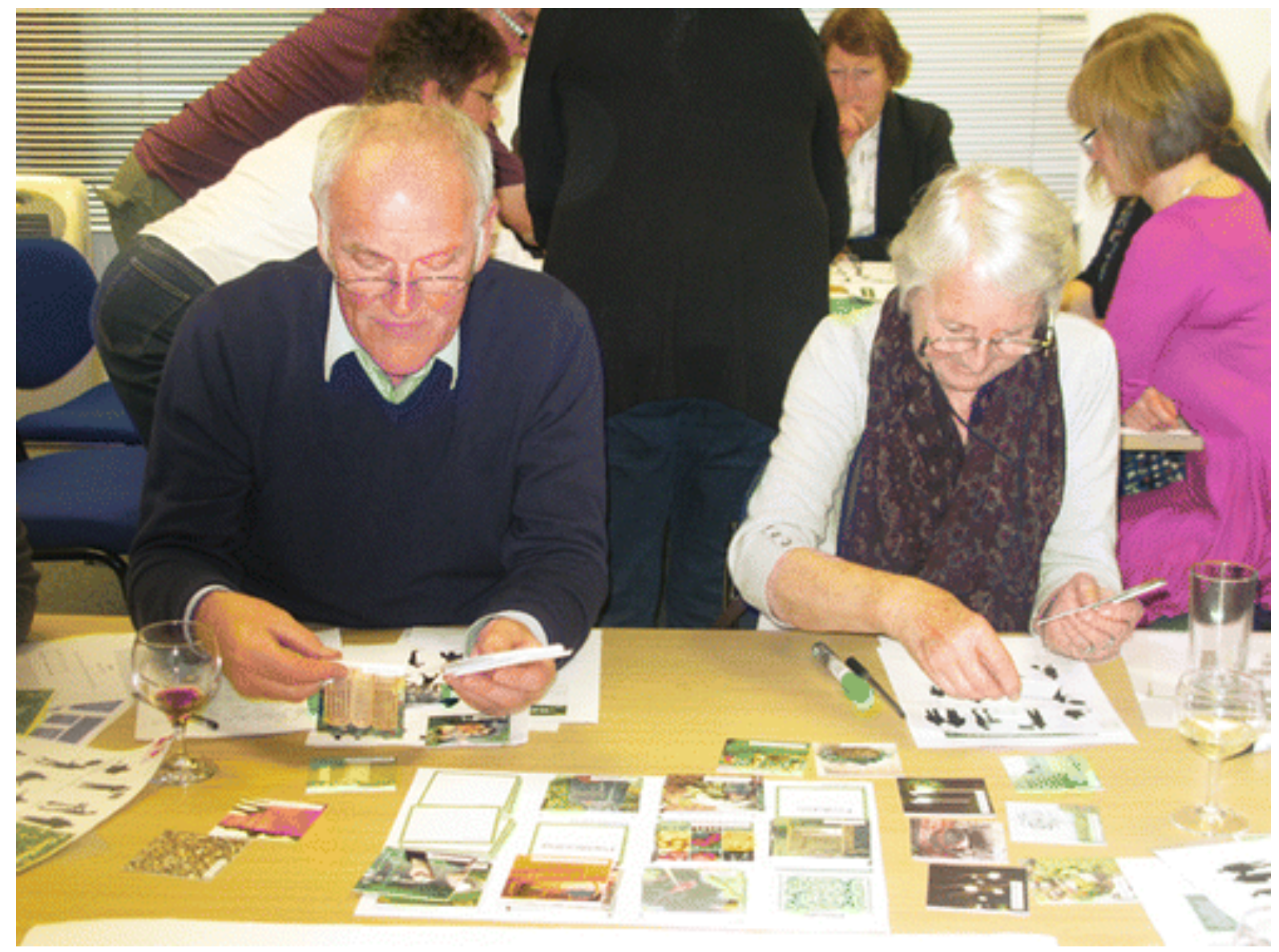

The exercise proved very useful in identifying recurring themes and engaging people to elicit revealing anecdotes. As the participants had to negotiate shared spaces, there was discussion and consensus on what should and should not be included, what should be grouped and what should stand alone.

\subsubsection{Ready Steady Make workshop}

Instead of interviews and conversations, the designer facilitated a series of creative workshops entitled Ready Steady Make for the support staff to explore the triad of strengths of the people they support in a less abstract but more concrete manner through the act of making. The workshops invited the participants to explore different themes by engaging in a variety of activities such as storyboarding, improvisation, playing games, making theatre sets and sensory props (Figure 10). An important aim was to use the process of making to encourage ideas exchange between staff. For example, the making of CD spinners sparked conversation about a man who loves spinning objects and has an impressive collection of windmill ornaments. This train of thought then prompted his support worker to plan a trip to a field of wind turbines, which proved a great success.

Figure 10 Ready Steady Make workshop. 


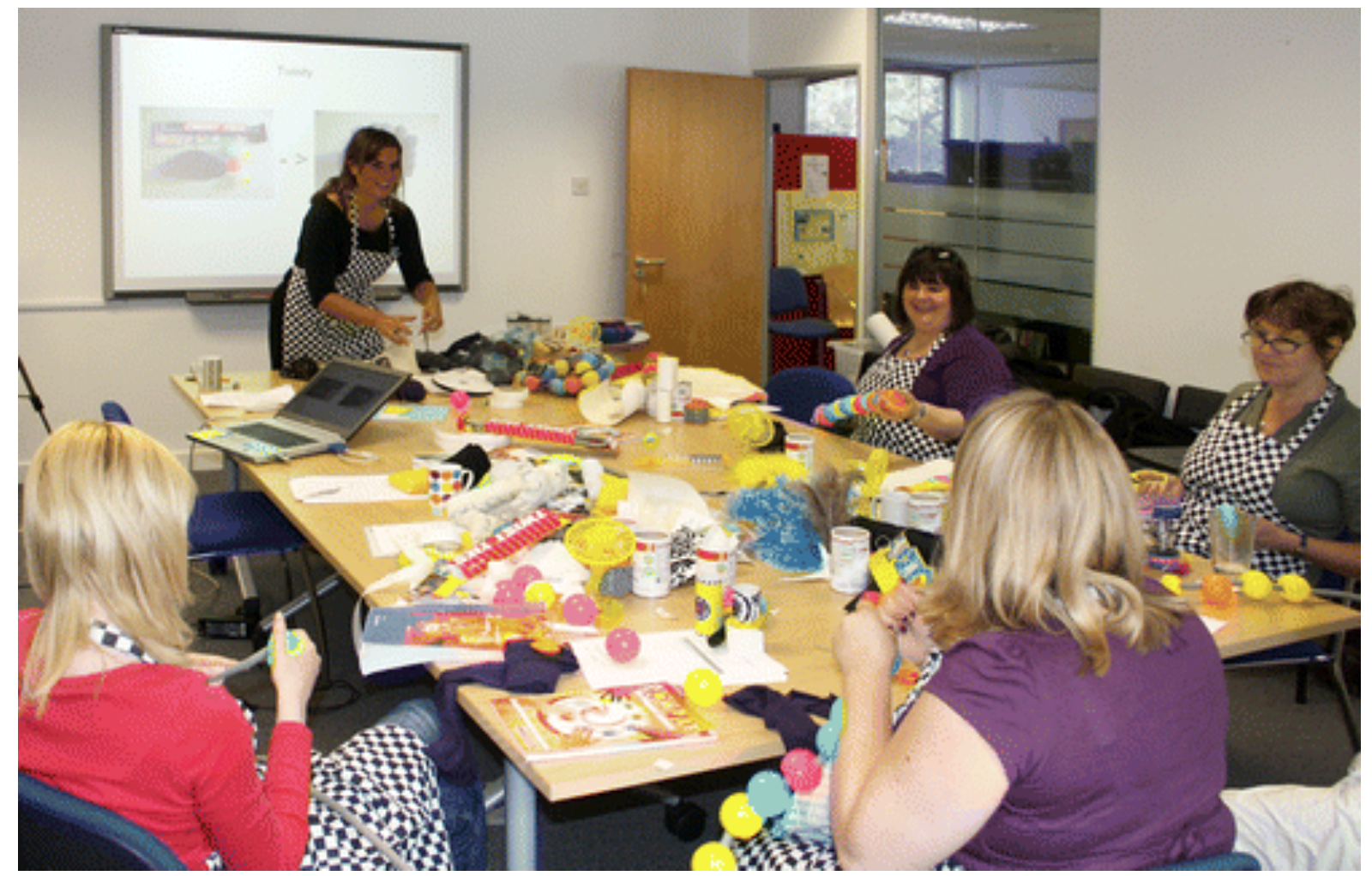

\subsubsection{Reflections}

The main challenge of the workshops was to steer discussions away from negative experiences and to manage expectations of what a co-creation workshop is. As the staff are used to attending more 'passive' training sessions, an interactive workshop where they were considered the experts, and learning was facilitated collaboratively, was at times met with cynicism.

\section{Summary; Design principles}

The design methods generated important information about a person's triad of strengths, revealing key insights: (1) a person's interest in the unintended affordance of everyday objects, i.e. enjoying the sound of desktop fans; (2) a person's choice of everyday activity can be influenced by their sensory preferences, i.e. putting cutlery away to hear it chime and (3) lastly, a person's special interests can influence their choice of what to do and how their home is decorated, i.e. one participant loves Thomas the Tank engine so much so that everything in her home is blue including her vacuum cleaner.

These insights led to design principles, which helped to guide the adaptation of the environment to complement a person's triad of strengths by (1) changing the affordance of the environment to incorporate an individual's specific focus of interest, (2) changing the affordance of the environment to incorporate a person's sensory preferences and (3) exploring ways to extend and enhance a person's interest with the unintended affordance of things, which in itself may inspire new design ideas that are meaningful and enjoyable for everyone. These insights in combination influenced the design process. For example, in stage one the designer observed a preference for the 'Henry' vacuum cleaner and the mapping tools in stage two revealed how activities involving bubbles such as washing up were really popular. Combining a person's interest (bubbles) with another activity such as 
vacuum cleaning was the inspiration for the design output: a bubble blowing vacuum cleaner.

\subsection{Summary; Design methods}

The designer used Sanders et al.'s (2010) participatory design framework (Figure 11), which describes and categorises design tools and techniques under different purposes, to help organise, reflect and communicate the design methods that amalgamated across the three design studies. This process helped decipher the existing participatory design methods that were relevant for the participants, and helped to identify any gaps and adjustments that were needed.

Figure 11 Sanders et al.'s (2010) participatory design framework.

\begin{tabular}{|c|c|c|c|c|c|c|c|c|}
\hline & \multicolumn{2}{|c|}{ PURPOSE } & \multirow[b]{2}{*}{ 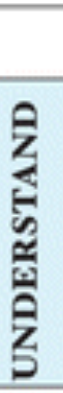 } & \multirow[b]{2}{*}{ 䩈 } & \multicolumn{3}{|c|}{ APPLICATION: } & \multirow[b]{2}{*}{ 岁 } \\
\hline $\begin{array}{l}\text { TOOLS AND } \\
\text { TECHNIQUES }\end{array}$ & 甶 & 我 & & & 点 & 今) & 它 & \\
\hline $\begin{array}{l}\text { MAKING TANGIBLE } \\
\text { THINGS }\end{array}$ & & & & & & & & \\
\hline $\begin{array}{l}\text { 2-D collages using visual and verbal } \\
\text { triggors on backgrounds with time- } \\
\text { lines, circles, etc. }\end{array}$ & & & & & & & & \\
\hline $\begin{array}{l}\text { 2-D mappings using visual and ver- } \\
\text { bal components on patterned back- } \\
\text { grounds }\end{array}$ & & & & & & & & \\
\hline $\begin{array}{l}\text { 3.D mock-ups using e.g. foam, clay, } \\
\text { Legos or Velcro-modeling }\end{array}$ & & & & & & & & \\
\hline $\begin{array}{l}\text { TALKING, TELLING } \\
\text { AND EXPLAINING }\end{array}$ & & & & & & & & \\
\hline $\begin{array}{l}\text { Stories and storyboarding through } \\
\text { witing, drawing, blogs, wiks, photos, } \\
\text { video. etc. }\end{array}$ & & & & & & & & \\
\hline $\begin{array}{l}\text { Diaries and daily logs through writing. } \\
\text { drawing. blogs, photos, video, etc. }\end{array}$ & & & & & & & & \\
\hline $\begin{array}{l}\text { Cards to organize, categorize and } \\
\text { pricitize ideas. The cards mey con- } \\
\text { tain vidoo snippets, incidents, signs, } \\
\text { traces, moments, photos, domains, } \\
\text { techoologies, templates and what if } \\
\text { provocations. }\end{array}$ & & & & & & & & \\
\hline $\begin{array}{l}\text { ACTING, ENACTING } \\
\text { AND PLAYING }\end{array}$ & & & & & & & & \\
\hline $\begin{array}{l}\text { Game boards and game pieces and } \\
\text { rules for playing }\end{array}$ & & & & & & & & \\
\hline Props and black boxes & & & & & & & & \\
\hline
\end{tabular}

Sander et al.'s participatory design framework was applied to each design study and to accommodate all of the design methods used, and several features were added to the framework (Figure 12); 'Communication' was added within the 'purpose' section, as exploring different ways of communicating without written and spoken language was central to the design methods. Equally, 'interacting', 'observing' and 'listening' were added alongside 'talking, telling and explaining'. Working 'one-to-one' was also added within the 
'application' section, as group situations were less appropriate compared to the one-to-one interactions presented in stage two. A new section was also added, entitled 'person'. The persons present within each design stage can strongly influence how the design methods are chosen and successfully deployed, for example, it is questionable as to how successful the design methods in Stage two would have been if the designer was present. Lastly, 'evaluate' was added to the purpose section. This was important when working with people who may not like changes to their environment and find it hard to express how they feel. Currently, all three design outputs are being evaluated.

Figure 12 Features added to the framework for design study two.

\begin{tabular}{|c|c|c|c|c|c|c|c|c|c|c|c|c|c|c|}
\hline DESIGN STUDY 2 & \multicolumn{3}{|c|}{ PURPOSE } & \multirow[b]{2}{*}{ 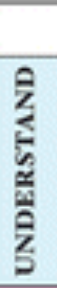 } & \multirow[b]{2}{*}{$\frac{\frac{1}{2}}{\frac{2}{2}}$} & \multirow[b]{2}{*}{$\frac{5}{5}$} & \multicolumn{4}{|c|}{ APPLICATION: } & \multirow[b]{2}{*}{$\frac{\frac{6}{3}}{\frac{1}{3}}$} & \multicolumn{3}{|c|}{ PERSON? } \\
\hline $\begin{array}{l}\text { TOOLS AND } \\
\text { TECHNIQUES }\end{array}$ & $\frac{6}{8}$ & $\frac{\sum^{3}}{2}$ & $\frac{2}{3}$ & & & & $\frac{3}{\frac{2}{3}}$ & 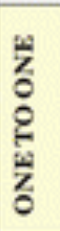 & $\frac{5}{5}$ & 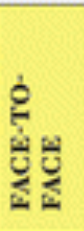 & & 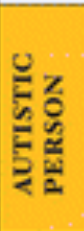 & 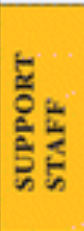 & $\frac{\frac{\pi}{0}}{\frac{0}{6}}$ \\
\hline $\begin{array}{l}\text { MAKING AND INTER- } \\
\text { ACTING WITH } \\
\text { TANGIBLE THINGS }\end{array}$ & & & & & & & & & & & & & & \\
\hline 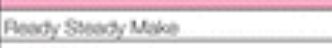 & & & & & & & & & & & & & & \\
\hline Sornoty Activios & & & & & & & & & & & & & & \\
\hline Shopy Banding & & & & & & & & & & & & & & \\
\hline boum Chanes Thas & & & & & & & & & & & & & & \\
\hline $\begin{array}{l}\text { OBSERVING, LISTEN- } \\
\text { ING, TALKING, TELL- } \\
\text { ING AND EXPLAINING }\end{array}$ & & & & & & & & & & & & & & \\
\hline Obiects of Evoryday Use Cands & & & & & & & & & & & & & & \\
\hline Doing Things Whi Things Bockets & & & & & & & & & & & & & & \\
\hline 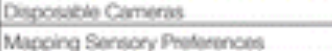 & & & & & & & & & & & & & & \\
\hline Mapoing Spocial reterenses & & & & & & & & & & & & & & \\
\hline Paricipatory Cbeervition & & & & & & & & & & & & & & \\
\hline Expert Audenenoe Group & & & & & & & & & & & & & & \\
\hline Shadowing & & & & & & & & & & & & & & \\
\hline $\begin{array}{l}\text { ACTING, ENACTING } \\
\text { AND PLAYING }\end{array}$ & & & & & & & & & & & & & & \\
\hline Meroring rtumests & & & & & & & & & & & & & & \\
\hline Making Theorre Sets & & & & & & & & & & & & & & \\
\hline
\end{tabular}

\section{Conclusions}

This project demonstrates how autistic adults with limited speech and additional learning disabilities (and their support staff) can be involved in the design process. However, the project also poses important questions, limitations and opportunities to inform future design research.

The design studies were not driven by preselected methods with specific aims and goals. Instead, each study evolved through the designer's empathic understanding, with each stage of the design process influencing the next. Therefore, it is not necessarily the development of autism-friendly design methods that is needed, but how the information derived from the design methods is disseminated and interpreted. Priority should be placed upon the designer's empathic understanding, as this proved to be the most important design method of all. Future design research would benefit from investigating how a neurotypical designer can empathise with a person whose sensory perceptual experiences are different to their own, and who may not be able to verbally communicate (Gaudion et al. 2014). 
A person's triad of strengths provided an important palette of ingredients for the designer and it is hypothesised that a person's sensory preferences, interests and action capabilities can influence their relationship with the environment. The triad of strengths can alternatively be perceived as a person's capabilities, which complements Gibson's concept of affordances and resonates with the capability approach developed by economist Sen (1999) and philosopher Nussbaum (2000). This project has attempted to create a framework for designers to investigate opportunities to explore a person's triad of strengths (capabilities) as a starting point to adapt environments that create positive experiences for people living with autism.

There are inherent difficulties in working with individuals who have learning disabilities and very little spoken language. To explore a person's everyday experiences, this work combines the views and experiences of multiple informants; the autistic adult, designer and support staff. Working with the autistic participants demands such triangulation. Whilst a co-design and a participatory design process in the traditional sense was not practiced with the autistic participants, the involvement of the autistic adults in the research significantly impacted on the process and design outputs. While different types and levels of participation were practiced throughout the project, the overarching thread that runs throughout is people-centred design. Central to every stage was the strengths and aspirations of the autistic adults, which were explored holistically through the triadic interactions between the autistic adults, support staff and designer.

Whilst the participants living with autism took part in activities and expressed their preferences, it is important to explore at what capacity they participated within the research. In models of participation (e.g. Arnstein 1969), the project falls between the consultation and placation stage of the ladder; the designer and support worker consult with an adult living with autism to share their preferences. Whether the research moved up the ladder beyond this stage remains unknown as it is difficult to ascertain whether the participants living with autism felt a sense of partnership and empowerment. However, the designer felt a genuine connection when interacting with each participant and as the design collaboration with Kingwood Trust continues, this reciprocal interaction will be explored further.

The project has highlighted the designer's own disengagement with the visceral qualities of the environment and the 'delightfulness' that this can encumber. The value of this research is to help to re-educate neurotypical designers to directly perceive (Gibson 1950) and experience the world not mediated cognitively through rational thought, but by reawakening their own physical engagement with the sensory qualities of the world around them; in other words bringing to the fore the 'delight' factor within the Conformity, Firmness and Delight synthesis ( $M$, Vitruvius). There is much neurotypical designers can learn from autistic people about improving everyday experiences for everyone.

\section{Acknowledgements}

The authors would like to thank Lady Hornby and Sue Osborn at the Kingwood Trust. They also thank Ted Powers, The Monument Trust, Colum Lowe (BEING) and members of the expert reference group for their ongoing support with the design collaboration. A special 
thanks goes to (for which it would have not been possible) to everyone that Kingwood Trust supports, their support staff and family members for their generosity of time, expertise and creative contributions to the research.

\section{Notes}

Consent has been granted for all photographs used within this paper. The real names of the participants have been replaced with pseudonyms to preserve anonymity. Throughout the paper, the term 'neurotypical' is used to describe people who are not autistic - a term widely used by the autism community. The term 'autistic' person is the preferred language of many people with autism (see Sinclair 1999). In this paper, we use this term as well as person-first language (such as 'adults living with autism') to respect the wishes of all people on the autistic spectrum.

\section{References}

1. AhrentzenS., and K.Steele. 2009. "Advancing Full Spectrum Housing: Designing for Adults with Autism Spectrum Disorders." Accessed October

12. http://stardust.asu.edu/docs/stardust/advancing-full-spectrum-housing/fullreport.pdf. [Google Scholar]

2. American Psychiatric Association. 2010. "Diagnostic and Statistical Manual of Mental Disorders -5 Development." Accessed November 2. www.dsm5.org/Pages/ Default.aspx. [Google Scholar]

3. ArnsteinS. R.1969. "A Ladder of Citizen Participation." Journal of the American Planning Association35 (4): 216-224. [Taylor \& Francis Online], [Web of Science

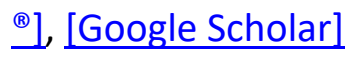

4. AspergerH.1944. "Autistic Psychopathy in Childhood." Translated and annotated by Frith U (1991) In Autism and Asperger Syndrome, edited by U.Frith, 3792. Cambridge, UK: Cambridge University Press. [Crossref], [Google Scholar]

5. BairdG., E.Simonoff, and A.Pickles. 2006. "Prevalence of the Disorders of the Autism Spectrum in a Population Cohort of Children in South Thames." The Lancet368: 210215. [Crossref], [PubMed], [Web of Science ${ }^{\circledR}$ ], [Google Scholar]

6. Baron-CohenS., and S.Wheelright. 1999. "Obsessions' in Children with Autism or Asperger's Syndrome. Content Analysis in Terms of Core Domains of Cognition." British Journal of Psychiatry175: 484-490. [Crossref], [PubMed], [Web of Science $\left.{ }^{\circledR}\right]$, [Google Scholar]

7. BaumersS., and A.Heylighen. 2010a. "Harnessing Different Dimensions of Space: The Built Environment in Auti-Biographies." In Designing Inclusive Interactions: Inclusive Interactions Between People and Products in Their Contexts of Use, edited by P.Langdon, P. J.Clarkson, and P.Robinson, 13-23. London: Springer. [Google Scholar]

8. BaumersS., and A.Heylighen. 2010b. "Beyond the Designers View: How People with Autism Experience Space." Proceedings, Design Research Society, Montréal, July 2-9. Accessed January 2013. https://lirias.kuleuven.be/bitstream/123456789/270650/3/008.pdf. [Google Scholar]

9. BeaverC.2003. "Breaking the Mold." Communication37 (3): 40. [Google Scholar]

10. BeaverC.2010. "Autism-Friendly Environments." The Autism File, no. 34: 8285. [Google Scholar] 
11. BeaverC.2011. "Designing Environments for Children and Adults on the Autism Spectrum." Good Autism Practice12 (1): 7-11. [Google Scholar]

12. BentonL., H.Johnson, M.Brosnan, E.Ashwin, and B.Grawemeyer. 2011. "IDEAS: An Interface Design Experience for the Autistic Spectrum." In Proceedings of the 2011 Annual Conference Extended Abstracts on Human Factors in Computing Systems, 1759-1764. New York: ACM press. [Crossref], [Google Scholar]

13. BentonL., and H.Johnson. 2014. "Structuring Participatory Design for Children: Can Typically Developing Children Benefit from Additional Support During the Design Process?" Instructional Science42 (1): 47-65. [Crossref], [Web of Science ${ }^{\circledR}$ ], [Google Scholar]

14. BrandA.2010. Living in the Community, Housing Design for Adults with Autism. London: The Helen Hamlyn Centre for Design, The Royal College of Art. [Google Scholar]

15. BrandA., and K.Gaudion. 2012. Exploring Sensory Preferences, Living Environments for Adults for Autism. London: The Helen Hamlyn Centre for Design, Royal College of Art. [Google Scholar]

16. BrughaT., S.McManus, H.Meltzer, J.Smith, F. J.Scott, S.Purdon, J.Harris, and J.Bankart. 2009. "Autism Spectrum Disorders in Adults Living in Households Throughout England." Report from the Adult Psychiatric Morbidity Survey 2007. [Google Scholar]

17. CaldwellP.2010. Autism and Intensive Interaction. London: Jessica Kingsley. [Google Scholarl

18. CashinA.2003. "A Hermeneutic Phenomenological Study of the Lived Experience of Parenting a Child with Autism." PhD diss., University of Technology, Sydney. [Google Scholar]

19. DeckerE.2014. "A City for Marc, an Inclusive Design Approach to Planning for Adults with Autism." Kansas State University. Accessed June 14. http://krex.kstate.edu/dspace/handle/2097/17606. [Google Scholar]

20. DruinA.1999. "Cooperative Inquiry: Developing New Technologies for Children with Children." In Proceedings of the SIGCHI Conference on Human Factors in Computing Systems: The $\mathrm{CHI}$ is the Limit, 592-599. Pittsburgh, PA: ACM. [Crossref], [Google Scholar]

21. DunnW.2002. "Adolescent / Adult Sensory Profile." Accessed Dec 2010. www. pearsonassessments.com/HAIWEB/Cultures/enus/Productdetail.htm?Pid = 076-1649-700. [Google Scholar]

22. FrancisP., S.Balbo, and L.Firth. 2009. "Towards Co-Design with Users who have Autism Spectrum Disorders." Universal Access Information Society8 (3): 123135. [Crossref], [Google Scholar]

23. FrauenbergerC., J.Good, A.Alcorn, and H.Pain. 2012a. "Supporting the Design Contributions of Children With Autism Spectrum Conditions." In Proceedings of the 12th International Conference on Interaction Design and Children, IDC'12, 134143. New York: ACM Press. [Crossref], [Google Scholar]

24. FrauenbergerC., J.Good, W.Keay-Bright, and H.Pain. 2012b. "Interpreting Input from Children: A Designerly Approach." In CHI '12: Proceedings of the 2012 Annual Conference on Human Factors in Computing Systems, edited by S.Bødker and D.Olsen, 2377-2386. New York: ACM Press. [Crossref], [Google Scholar] 
25. FrauenbergerC., J.Good, and W.Keay-Bright. 2010. "Phenomenology, a Framework for Participatory Design." In Proceedings of the 11th Biennial Participatory Design Conference, 187-190. New York: ACM Press. [Crossref], [Google Scholar]

26. FrauenbergerC., J.Good, and W.Keay-Bright. 2011. "Designing Technology for Children with Special Needs - Bridging Perspectives through Participatory Design." CoDesign: International Journal of CoCreation in Design and the Arts7 (1): 128. [Web of Science ${ }^{\circledR}$, [Google Scholar]

27. GaudionK.2013. Designing Everyday Activities, Living Environments for Adults with Autism. London: The Helen Hamlyn Centre for Design, Royal College of Art. [Google Scholar]

28. GaudionK.2014. Picture-It, a Digital Tool to Support Living with Autism. London: The Helen Hamlyn Centre for Design, The Royal College of Art. [Google Scholar]

29. GaudionK., A.Hall, J.Myerson, and L.Pellicano. 2014. "Design and Wellbeing: Bridging the Empathy Gap Between Neurotypical Designers and People with Autism." In Design for Sustainable Well-Being and Empowerment: Select Papers. Indian Institute of Science and TU Delft Joint Publication. [Google Scholar]

30. GaudionK., and C.McGinley. 2012. Green Spaces; Outdoor Environments for Adults with Autism. London: The Helen Hamlyn Centre for Design, The Royal College of Art. [Google Scholar]

31. GernsbacherM. A.2006. "Towards a Behavior of Reciprocity." Journal of Developmental Processes1 (1): 139-157. [Google Scholar]

32. GibsonJ. J.1950. The Perception of the Visual World. Boston: Houghton Mifflin. [Crossref], [Google Scholar]

33. GibsonJ. J.1977. "The Theory of Affordances." In Perceiving, Acting and Knowing, edited by R.Shaw and J.Bransford, 67-82. Hillsdale, NJ: Erlbaum. [Google Scholar]

34. GibsonJ. J.1979. The Ecological Approach to Visual Perception. Boston: Houghton Mifflin. [Google Scholar]

35. MadsenM., et al. 2009. "Lessons from Participatory Design with Adolescents on the Autism Spectrum." In CHI'09 Extended Abstracts on Human Factors in Computing Systems, 3835-3840. New York: ACM. [Crossref], [Google Scholar]

36. GuhaM., A.Druin, and J.Fails. 2008. "Designing with and for Children with Special Needs: An Inclusionary Model." IDC '08 Proceedings of the 7th international conference on interaction design and children61-64. New York: ACM. [Google Scholarl

37. GumtauS., P.Newland, C.Creed, and S.Kunath. 2005. "MEDIATE - A Responsive Environment Designed for Children with Autism." Accessed September 21. http://ewic.bcs.org/content/ConWebDoc/3805. [Google Scholar]

38. HerbertB.2003. "Design Guidelines of a Therapeutic Garden for Autistic Children." PhD diss., Louisiana State University. Accessed October 12. http://etd.Isu.edu/docs/available/etd-0127103. [Google Scholar]

39. HourcadeJ. P., N. E.Bullock-Rest, and T. E.Hansen. 2012. "Multitouch Tablet Applications and Activities to Enhance the Social Skills of Children with Autism Spectrum Disorder." Personal and Ubiquitous Computing16 (2): 157168. [Crossref], [Web of Science ${ }^{\circledR}$ ], [Google Scholar]

40. HumphreyS.2005. "Autism and Architecture." Autism London Bulletin, 7-8. [Google Scholar] 
41. HusseinH.2010. "Using the Sensory Garden as a Tool to Enhance the Educational Development and Social Interaction of Children with Special Needs." Support for Learning. 25 (1): 25-31. [Crossref], [Google Scholar]

42. KannerL.1943. "Autistic Disturbances of Affective Contact." Nervous Child2: 217250. [Google Scholar]

43. KanakriS.2013. "The Impact of Acoustical Environmental Design on Children with Autism." Journal of Alzheimer's Disorder Parkinsonism3 (4): 54-59. [Google Scholar]

44. Keay-BrightW.2007. "The Reactive Colours Project: Demonstrating Participatory and Collaborative Design Methods for the Creation of Software for Autistic Children." Design Principles and Practices: An International Journal1 (2): 28-35. [Google Scholarl

45. Keay-BrightW.2009. "ReacTickles: Playful interaction with Information Communication Technologies." International Journal of Art \& Technology2 (1/2): 133-151. [Crossref], [Google Scholar]

46. Keay-BrightW.2012a. "Designing Interaction Through Sound and Movement with Children on the Autistic Spectrum." Arts and Technology: Lecture Notes of the Institute for Computer Science, Social Informatics and Telecommunications Engineering101: 1-9. [Crossref], [Google Scholar]

47. Keay-BrightW.2012b. "Is Simplicity the Key to Engagement for Children on the Autism Spectrum?" Journal of Personal and Ubiquitous Computing16: 129141. [Crossref], [Web of Science ${ }^{\circledR}$ ], [Google Scholar]

48. KhareR., and A.Mullick. 2010. "Universally Beneficial Educational Space Design for Children with Autism." Presented in 'Designing for Children' with focus on 'Play+Learn.' Bombay, India. [Google Scholar]

49. LawtonM. P., and E. M.Brody. 1969. "Assessment of Older People: Selfmaintaining and Instrumental Activities of Daily Living." The Gerontologist9 (3): 179186. [Crossref], [PubMed], [Web of Science ${ }^{\circledR}$ ], [Google Scholar]

50. LinehanJ.2008. "Landscapes for Autism: Guidelines and Design of Outdoor Spaces for Children with Autism Spectrum Disorder." Thesis, University of California. Accessed March 3. http://lda.ucdavis.edu/people/2008/JLinehan.pdf. [Google Scholar]

51. LopezK., and K.Gaines. 2012. Proceedings of the 43rd Annual Conference of the Environmental Design Research Association. 265-266. Accessed October 11. http://www.edra.org/content/environment-and-behavior-residential- designsautism "Environment and Behavior: Residential Designs for Autism." [Google Scholarl

52. LovelandK. A.1991. "Social Affordances and Interaction II: Autism and the Affordances of the Human Environment." Ecological Psychology3 (2): 99-119. [Taylor \& Francis Online], [Google Scholar]

53. LovelandK. A.1994. "Autism, Affordances and the Self." In The Perceived Self, Ecological and Interpersonal Sources of Self-Knowledge, edited by U.Neissser, 237253. Cambridge: Cambridge University Press. [Crossref], [Google Scholar]

54. LovelandK. A.2001. "Towards an Ecological Theory of Autism." In The Development of Autism: Perspectives from Theory and Research, edited by J.Burack, T.Charman, N.Yirmiya, and P. R.Zelazo, 17-37. Mahwah, NJ: Erlbaum Press. [Google Scholar]

55. MaceW. M.1977. "James J. Gibson's Strategy for Perceiving: Ask not what's Inside Your Head, But What Your Head's Inside Of." In Perceiving, Acting, and Knowing: 
Toward an Ecological Psychology, edited by R.Shaw and J.Bransford, 43-67. Hillsdale, NJ: Erlbaum. [Google Scholar]

56. McAllisterK., and B.Maguire. 2012. "A Design Model: The Autism Spectrum Disorder Classroom Design Kit." British Journal of Special Education39 (4): 201208. [Crossref], [Google Scholar]

57. MenearK. S., S. C.Smith, and S.Lanier. 2006. "A Multipurpose Fitness Playground for Individuals with Autism: Ideas for Design and Use." Journal of Physical Education, Recreation and Dance77 (9): 20-25. [Taylor \& Francis Online], [Google Scholar]

58. MostafaM.2008. "An Architecture for Autism: Concepts of Design Intervention for Autistic User." International Journal of Architectural Research2 (1): 189-211. [Google Scholar]

59. NindM., and D.Hewett. 1994. Access to Communication. London: David Fulton. [Google Scholar]

60. Norberg-SchulzC.1991. Genius Loci: Towards a Phenomenology of Architecture. New York: Rizzoli. [Google Scholar]

61. NussbaumM. C.2000. Women and Human Development: The Capability Approach. New York: Cambridge University Press. [Crossref], [Google Scholar]

62. ParsonsS., L.Beardon, H. R.Neale, et al. 2000. "Development of Social Skills Amongst Adults with Asperger's Syndrome using Virtual Environments: The 'AS Interactive' Project." Proceedings of The 3rd International Conference on Disability, Virtual Reality and Associated Technologies, ICDVRAT, 2000. [Google Scholar]

63. PellicanoE., A.Dinsmore, and T.Carman. 2013. A Future Made Together: Shaping Autism Research in the UK. London: Institute of Education. [Google Scholar]

64. PellicanoE., A.Dinsmore, and T.Carman. 2014. "What Should Autism Research Focus Upon? Community Views and Priorities from the United Kingdom." Autism18 (7): 756-770. [Crossref], [PubMed], [Web of Science ${ }^{\circledR}$ ], [Google Scholar]

65. RicherJ., and S.Nicoll. 1971. "The Physical Environment of the Mentally Handicapped: A Playroom for Autistic Children, and its Companion Therapy Project." British Journal of Mental Subnormality2 (33): 132-143. [Taylor \& Francis Online], [Google Scholar]

66. RobinsonA.2012. "Sensory Experiences of Individuals with Autism Spectrum Disorder and Autistic Traits: A Mixed Methods Approach." PhD diss., University of Glasgow. [Google Scholar]

67. SachsN., and T.Vincenta. 2011. "Outdoor Environments for Children with Autism and Special Needs." Implications. 9(1) online newsletter for Informedesign. Accessed October 12. http://www.informedesign.org/ news/april v09-p.pdf. [Google Scholar]

68. SanchezP., F.Vázque, and L.Serrano. 2011. "Autism and the built environment." In Autism Spectrum Environments - from Genes to Environment, edited by Tim Williams. Intech Croatia. Accessed November 2013. http://cdn.intechweb.org/pdfs/19213.pdf. [Google Scholar]

69. SandersL., EBrandt, and T.Binder. 2010. "A Framework for Organizing the Tools and Techniques of Participatory Design." Proceedings of the 11th Biennial Participatory Design Conference, 195-198. Accessed December 10. http://www.maketools.com/articlespapers/PDC2010ExploratoryFrameworkFinal.pdf. [Crossref], [Google Scholar]

70. SeamonD., and R.Mugerauer. 2000. Dwelling, Place \& Environment: Towards a Phenomenology of Person and World. Florida: Krieger Publishing. [Crossref], [Google Scholar] 
71. SeamonD.1993. Dwelling, Seeing and Designing: Towards a Phenomenological Ecology. Albany: State University of New York Press. [Google Scholar]

72. SenA.1999. Development as Freedom. New York: Anchor Books. [Google Scholar]

73. SinclairJ.1999. "Why I dislike 'person first' Language." Accessed February 11. http://bit.ly/X3bWvS. [Google Scholar]

74. SirowyB.2010. "Phenomenological Concepts in Architecture: Towards a User Orientated Practice." Accessed January

20. http://www.aho.no/pagefiles/1752/thesis\%20sirowy.pdf. [Google Scholar]

75. TufvessonC., and J.Tufvesson. 2009. "The Building Process as a Tool Towards an AllInclusive School. A Swedish Example Focusing on Children with Defined Concentration Difficulties Such as ADHD, Autism and Down's Syndrome." Journal of Housing and the Built Environment24 (1): 47-66. [Crossref], [Web of Science

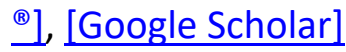

76. WilliamsE., and L.Kendell Scott. 2006. "Autism and Object Use: The Mutuality of the Social and Material in Children's Developing Understanding and Use of Everyday Objects." In Doing Things with Things, the Design and Use of Everyday Objects, edited by A.Costall and O.Dreier. 3, 47-51. London: Ashgate. [Google Scholar]

77. WilliamsE., A.Costall, and V.Reddy. 1999. "Children with Autism Experience Problems with Both Objects and People." Journal of Autism and Developmental Disorders29 (5): 367-378. [Crossref], [PubMed], [Web of Science ${ }^{\circledR}$ ], [Google Scholar]

78. WilliamsE., L.Kendell-Scott, and A.Costall. 2005. "Parents' Experiences of Introducing Everyday Object use to their Children with Autism." Autism9 (5): 495514. [Crossref], [PubMed], [Web of Science ${ }^{\circledR}$ ], [Google Scholar]

79. WoodcockA., D.Georgiou, J.Jackson, and A.Woolner. 2006. "Designing a Tailorable Environment for Children with Autism Spectrum Disorders. The Design Institute, Coventry." Accessed October 11. http://www.iea.cc/ECEE/pdfs/art0228.pdf. [Google Scholar]

80. Van RijnsH.2012. "Meaningful Encounters; Explorative Studies about Designers Learning from Children with Autism." PhD diss., TU Delft. [Google Scholar]

81. VogelC. L.2008. "Classroom Design for Living and Learning with Autism." Autism Asperger's Digest. [Google Scholar]

82. YuillN., S.Strieth, C.Roake, R.Aspen, and B.Todd. 2007. "Brief Report: Designing a Playground for Children Autistic Spectrum Disorder: Effects on Playful Peer Interactions." Journal of Autism Developmental Disorders.37 (6): 11921196. [Crossref], [PubMed], [Web of Science ${ }^{\circledR}$ ], [Google Scholar] 